\title{
Optimization of Friction and Wear Behaviour in Hybrid Metal Matrix Composites Using Taguchi Technique
}

\author{
V. C. Uvaraja ${ }^{1 *}$, N. Natarajan ${ }^{2}$ \\ ${ }^{1}$ Department of Mechanical Engineering, Bannari Amman Institute of Technology, Sathyamangalam, India \\ ${ }^{2}$ Suguna College of Engineering, Coimbatore, India \\ Email: *c_uva@rediffmail.com
}

Received February 5, 2012; revised March 12, 2012; accepted March 31, 2012

\begin{abstract}
Al-7075 alloy-base matrix, reinforced with mixtures of silicon carbide $(\mathrm{SiC})$ and boron carbide $\left(\mathrm{B}_{4} \mathrm{C}\right)$ particles, know as hybrid composites have been fabricated by stir casting technique (liquid metallurgy route) and optimized at different parameters like sliding speed, applied load, sliding time, and percentage of reinforcement by Taguchi method. The specimens were examined by Rockwell hardness test machine, Pin on Disc, Scanning Electron Microscope (SEM) and Optical Microscope. A plan of experiment generated through Taguchi's technique is used to conduct experiments based on $\mathrm{L}_{27}$ orthogonal array. The developed ANOVA and the regression equations were used to find the optimum wear as well as coefficient of friction under the influence of sliding speed, applied load, sliding time and percentage of reinforcement. The dry sliding wear resistance was analyzed on the basis of "smaller the best". Finally, confirmation tests were carried out to verify the experimental results.
\end{abstract}

Keywords: Hybrid Metal Matrix Composites; Stir-Cast; Dry Sliding Wear, Orthogonal Array; Taguchi Technique; Analysis of Variance

\section{Introduction}

Two phases namely a matrix phase and a reinforcement phase constitute composite materials. Matrix and reinforcement phase work together to produce combination of material properties that cannot be met by the conventional materials [1]. In this study the composite is produced by using stir casting method, which is one of the economic and commonly used methods in Liquid Metallurgy. Most of studies made in automotive and aerospace field shows that the material used for components should posses good toughness with better tribological properties. Hence to meet the automotive application requirements an attempt has been made to develop the Al-7075 based hybrid composite, having combination of both toughness and tribological properties like wear resistance. The greatest improvement in tribological properties of composite is generally obtained using particle reinforcement of silicon carbide and boron carbide. Yoshiro Iwai et al. [2] found that the initial sliding distance require to achieve mild wear decreased with increasing volume fraction and also wear rate decrease linearly with volume fraction. Daoud et al. [3] reported that the addition of magnesium alloy to composite during production ensures good bonding between the matrix and the reinforcement.

\footnotetext{
"Corresponding author.
}

Aluminum alloys possess a number of mechanical and physical properties that make them attractive for automotive applications, but they exhibit extremely poor resistance to seizure and galling [4]. N. Natarajan et al. [5] recommended $\mathrm{SiC}$ particulate reinforcement of metal matrix is more appropriate aspirant material for automobile purpose, but a new friction material is to be developed. S. Basavarajappa et al. [6] inspected in detail sliding speed, load, sliding distance, percentage of reinforcement and mutual effect of these factors, which manipulate the dry sliding wear performance of matrix alloy (Al-2219) reinforced with SiC. N. Radhika et al. [7] found taguchi technique as a valuable technique to deal with responses influenced by multi-variables. It is formulated for process optimization and detection of optimal combination of the parameters for a given response. This method significantly reduces the number of trials that are required to model the response function compared with the full factorial design of experiments. The most important benefit of this technique is to find out the possible interaction between the factors. In view of the above article, an assessment is made to investigate the outcome of sliding speed, load, sliding time and volume fraction of reinforcement on the dry sliding wear behavior of the particulate reinforced Al-7075 alloy with a constant weight percentage $(3 \%)$ of $\mathrm{B}_{4} \mathrm{C}$ particulate and 
varying range $(5 \%, 10 \%, 15 \%)$ of $\mathrm{SiC}$ particulate composites using taguchi method. The Analysis of variance was used to find the percentage contribution (Pr) of various process parameters and their correlations on dry sliding wear of the hybrid composite materials.

\section{Material Selection}

In the present investigation, Dry sliding wear tests were performed on $\mathrm{SiC}$ and $\mathrm{B} 4 \mathrm{C}$ particulates reinforced $\mathrm{Al}$ 7075 alloy matrix composite. The Al-Mg-Si base alloys were purchased from Metal Mart Pvt. Ltd., Coimbatore (Tamil Nadu) India. Table 1 shows the nominal composition weight percentage of matrix materials. The hardness measurements were made by applying a load of $100 \mathrm{~kg}$ and the average is calculated from 10 different values of the experiments. The density measurements were all set according to the ASTM standard C1270-88. The value of hardness and density for matrix material were $67.17 \mathrm{HRC}$ and $2.81 \mathrm{~g} / \mathrm{m}^{3}$ respectively in tempered condition. The particulate morphology study results such as shape of both reinforcements were angular-irregular and size of $\mathrm{SiC}(30 \mu \mathrm{m}-70 \mu \mathrm{m})$ and $\mathrm{B}_{4} \mathrm{C}(5$ $\mu \mathrm{m}-20 \mu \mathrm{m})$.

\subsection{Manufacturing of the Hybrid Composites Material}

Stir casting technique is one of the popular Liquid Metallurgy Route (LMR) and also known as a very promising route for manufacturing near net shape hybrid metal matrix composite components at a normal cost [8]. In this present work, stir casting technique was used to fab- ricate Al-7075 alloy with varying weight percentages of $\mathrm{SiC}(5 \%, 10 \%$, and $15 \%)$ and a constant weight percentage of $\mathrm{B}_{4} \mathrm{C}(3 \%)$ reinforcements. In order to achieve good binding between the matrix and particulates, one weight percent of magnesium alloy is added. The experimental set up was shown in Plate 1. The stir casting furnace is mounted on the floor and the temperature of the furnace is precisely measured and controlled in order to achieve sound quality composite. Two thermocouples and one PID controller were used for this purpose. As mild steel materials are having high temperature stability, they are selected as stirrer rod and impeller.

This stirrer was connected to 1HP DC Motor through flexible link and was used to stir the molten metal in semi solid state. The screw operator lift is used to bring the stirrer in contact with the composite material. The melt was maintained at a temperature between $800^{\circ} \mathrm{C}$ to $875^{\circ} \mathrm{C}$ for one hour. Vortex was created by using a mechanical stirrer. Weighed quantity of $\operatorname{SiC}(5,10$ and 15 wt $\%$ ) along with 3 weight percentage of $\mathrm{B}_{4} \mathrm{C}$ particulate, preheated to $600^{\circ} \mathrm{C}$ were added to the melt with constant stirring for about $10 \mathrm{~min}$ at 500 to $650 \mathrm{rpm}$. After complete addition of the particles to the melt, the composite alloy was tilt poured into the preheated $\left(300^{\circ} \mathrm{C}\right)$ permanent steel mould and allowed to cool in atmospheric air. The billet was then removed from the mould and machined for required dimensions. The uniform distribution of particulates reinforced in the matrix was examined with the help of Optical-Microscope. The optical micrographs of unreinforced alloy and the composite with 5, $10,15 \mathrm{wt} \%$ of reinforcement are shown in Plates 2-5 respectively.

Table 1. Chemical composition of the matrix alloy.

\begin{tabular}{cccccccccc}
\hline $\mathrm{Si}$ & $\mathrm{Fe}$ & $\mathrm{Cu}$ & $\mathrm{Mn}$ & $\mathrm{Mg}$ & $\mathrm{Cr}$ & $\mathrm{Ni}$ & $\mathrm{Zn}$ & $\mathrm{Ti}$ & $\mathrm{Ag}$ \\
$>0.130$ & $>0.203$ & 1.62 & 0.074 & 2.42 & 0.183 & 0.03 & $>3.6$ & 0.049 & 0.024 \\
$\mathrm{~B}$ & $\mathrm{Be}$ & $\mathrm{Bi}$ & $\mathrm{Ca}$ & $\mathrm{Cd}$ & $\mathrm{Co}$ & $\mathrm{Li}$ & $\mathrm{Na}$ & $\mathrm{P}$ & $\mathrm{Pb}$ \\
0.0025 & 0.001 & 0.0013 & 0.0005 & 0.0003 & 0.0003 & $<0.0010$ & $<0.0002$ & 0.0005 & $<0.0010$ \\
$\mathrm{Sn}$ & $\mathrm{Sr}$ & $\mathrm{V}$ & $\mathrm{Zr}$ & $\mathrm{Al}$ & & & & & \\
0.004 & $<0.0001$ & 0.0066 & 0.0056 & 90.52 & & & & & \\
\hline
\end{tabular}

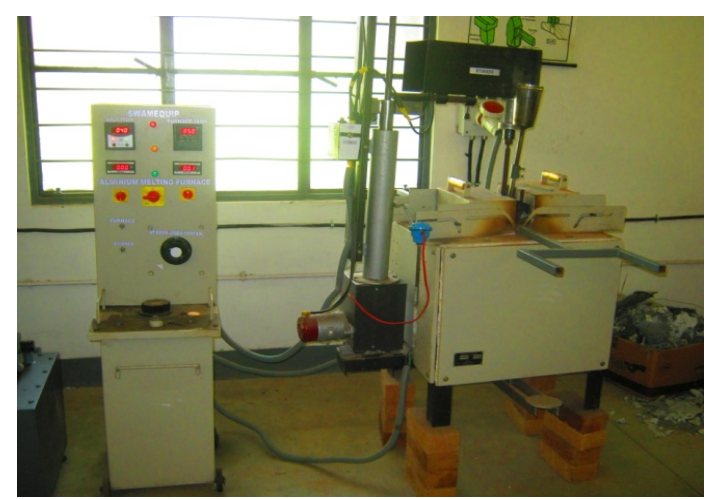

Plate 1. Stir casting setup. 


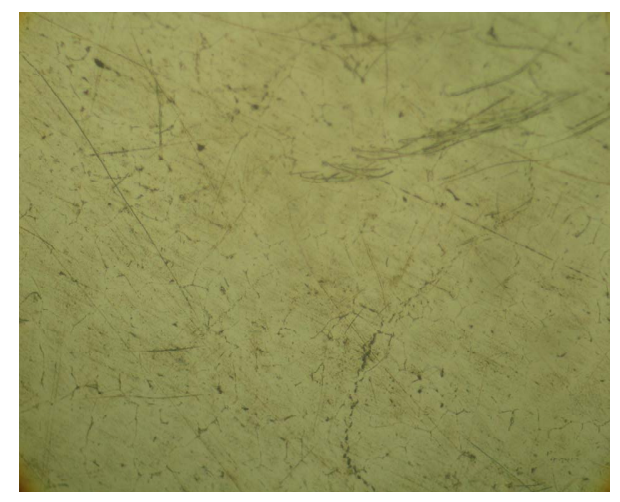

Plate 2. Optical Microscopic image of unreinforced Al (7075) alloy at $100 \times$ magnification.

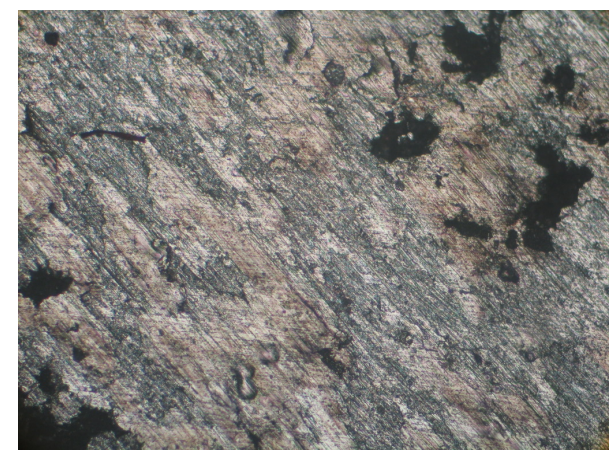

Plate 4. Optical Microscope image of $10 \% \mathrm{SiC}+3 \% \mathrm{~B}_{4} \mathrm{C}$ particulate reinforced $\mathrm{Al}(7075)$ composite at $100 \times$ magnification.

\subsection{Microstructure and Hardness}

The resistance indentation or scratch is termed as hardness. Hardness test was carried out at room temperature using Rockwell hardness tester with at least six indentations of each sample and then the average values were utilized to calculate hardness number. The hardness of MMC increases with the volume fraction of particulate in the alloy matrix. The added amount of $\mathrm{SiC}$ and $\mathrm{B}_{4} \mathrm{C}$ particles enhances hardness, as these particles are harder than Al alloy rendering their inherent property of hardness to soft matrix as shown in Figure 1. Composites with higher hardness could be achieved by this technique which may be due to the fact that silicon carbide and boron carbide particles act as obstacles to the motion of dislocation.

The hardness graph shows that the sample with less than $5 \mathrm{wt} \%$ of $\mathrm{SiC}$ and $3 \mathrm{wt} \% \mathrm{~B}_{4} \mathrm{C}$ particulate behaves almost the same as unreinforced. But the sample with 15 $\mathrm{wt} \% \mathrm{SiC}$ and $3 \mathrm{wt} \% \mathrm{~B}_{4} \mathrm{C}$ showed slightly high hardness and low toughness as compare to $10 \mathrm{wt} \% \mathrm{SiC}$ and $3 \mathrm{wt} \%$ $\mathrm{B}_{4} \mathrm{C}$. Higher the percentage of particulates in the matrix, lesser is the toughness. Therefore, from this study it is evidently indicated that $10 \mathrm{wt} \% \mathrm{SiC}$ and $3 \mathrm{wt} \%$ boron

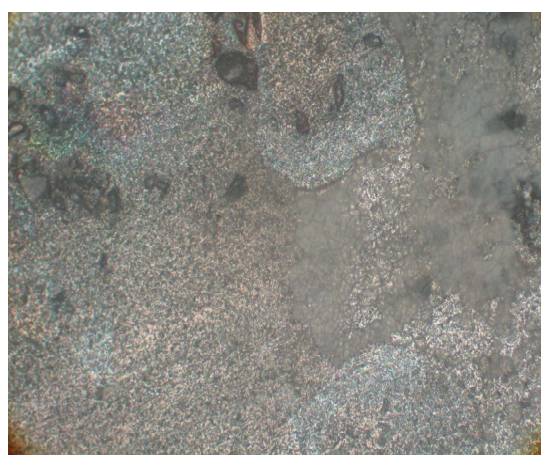

Plate 3. Optical Microscope image of $5 \% \mathrm{SiC}+3 \% \mathrm{~B}_{4} \mathrm{C}$ particulate reinforced $\mathrm{Al}(\mathbf{7 0 7 5 )}$ composite at $100 \times$ magnification.

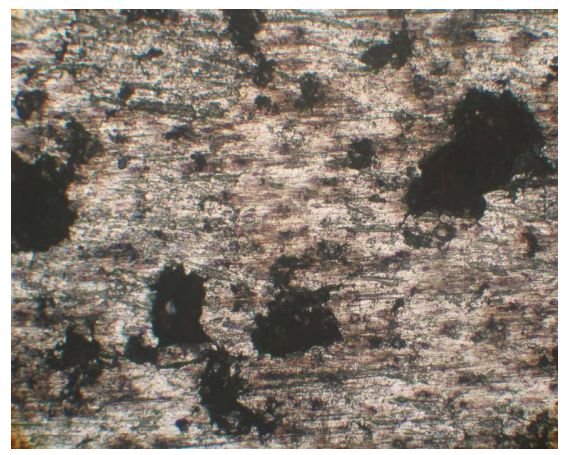

Plate 5. Optical Microscope image of $15 \% \mathrm{SiC}+3 \% \mathrm{~B}_{4} \mathrm{C}$ particulate reinforced $\mathrm{Al}$ (7075) composite at $100 \times$ magnification.

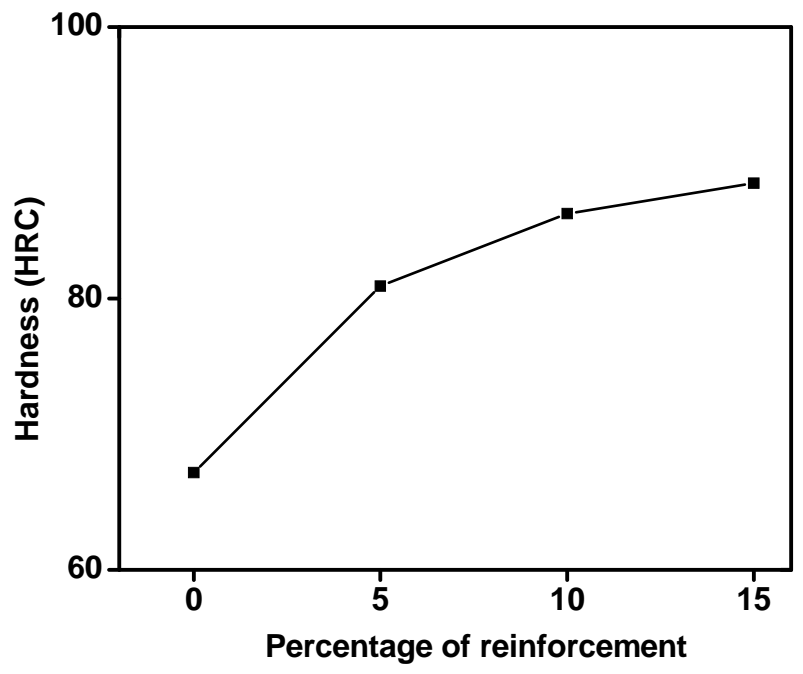

Figure 1. Hardness of unreinforced alloy and composites at different volume fraction.

carbide composite sample have high hardness and good toughness. Hence this may be considered as the optimum weight percentage of the particulate to achieve better hybrid composite properties for heavy vehicle applications. 


\subsection{Mechanism of Wear Test}

The composite specimens were rubbed against hardened steel. Dry sliding wear tests were carried out using pinon-disc type wear tester at different parameters like sliding speed, applying load, Sliding time and percentage of reinforcement were varied in the range given in Table 2.

Plate 6 shows the complete pin-on-disc wear test experimental setup. The slider disc is made up of $0.95 \%$ to $1.20 \%$ carbon (EN31) hardened steel disc with hardness of $62 \mathrm{HRC}$ having diameter $165 \mathrm{~mm}$. The pin test sample dimensions were $12 \mathrm{~mm}$ diameter and $32 \mathrm{~mm}$ height. Care should be taken to note that the test sample's end surfaces were flat and polished metallographically prior to testing. Conventional aluminium alloy polishing techniques were used to get ready the contact surfaces of the monolithic composite aluminium specimen for wear test. The procedure involves grinding of composite aluminium surfaces manually by $240,320,400$ and 600 grit silicon carbide papers and then polishing them with 5, 1 $\& 0.5 \mu \mathrm{m}$ alumina using low speed polishing machine. This preparation technique created considerable surface relief between hard and soft aluminium matrix. The polished surfaces were cleaned ultrasonically with acetone and methanol solutions.

The counter face materials were also polished and cleaned ultrasonically in acetone and methanol solutions before each wear test. The steel slider was polished using the above described procedure and all the tests were conducted at room temperature. The wear rates measured in weight units were obtained by weighing the specimen before and after the experiment and then converted to volumetric wear rates. The micro structural investigation and semi quantitative chemical analysis on the worn surfaces were performed by SEM.

Table 2. Process parameters and levels.

\begin{tabular}{ccccc}
\hline Level & $\begin{array}{c}\text { Speed } \\
(\mathrm{m} / \mathrm{s})\end{array}$ & $\begin{array}{c}\text { Load } \\
(\mathrm{N})\end{array}$ & $\begin{array}{c}\text { Time } \\
(\mathrm{min})\end{array}$ & $\begin{array}{c}\text { Percentage of } \\
\text { Reinforcement \% }\end{array}$ \\
\hline 1 & 1.5 & 10 & 5 & 5 \\
2 & 3 & 20 & 10 & 10 \\
3 & 4.5 & 40 & 15 & 15 \\
\hline
\end{tabular}

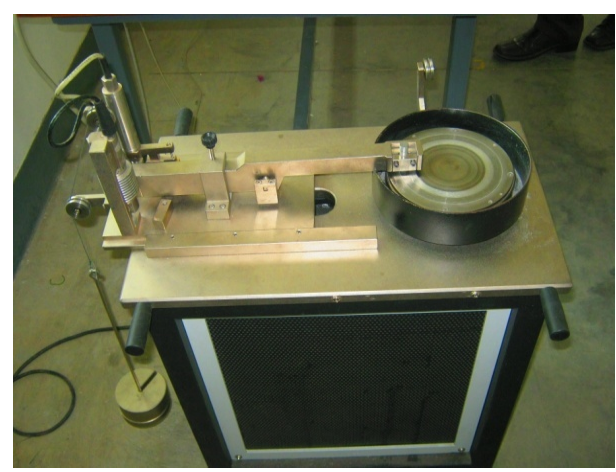

Plate 6. A pin-on-disc wear testing machine.

\section{Design of Experiment}

An experiment is designed in such a way to evaluate simultaneously two or more factors which possess their ability to affect the resultant average or variability of particular product or process characteristics. To accomplish this in an effective and statistically proper fashion, levels of the factors are varied in a strategic manner. The results of the particular test combinations are observed and the complete set of results are analyzed to determine the preferred level of the various influencing factors whether increases or decreases of those levels will potentially lead to further improvement [9]. The design of experiment process is divided into three main phases or planning phases namely, the conducting phase and the analysis phase, which encompass all experimentation approaches.

Investigation of the experimental outcomes uses signal to noise ratio to support the determination of the finest process design. This method is effectively used to study of dry sliding wear behavior of composites materials [10]. In this work, the "smaller the best" quality characteristics were taken to finding the minimum wear rate and coefficient of friction.

\section{Plan of Experiment}

The experiments were conduct as per the standard orthogonal array. The selection of the orthogonal array is based on the condition that the degrees of freedom for the orthogonal array should be greater than or at least equals sum of those of wear parameters. In the present investigation an $\mathrm{L}_{27}\left(3^{13}\right)$ orthogonal array was chosen as shown in Figure 2, which has 27 rows corresponding to the number of tests ( 20 degrees of freedom) and 13 columns at three levels and four factors, as shown in Table 3.

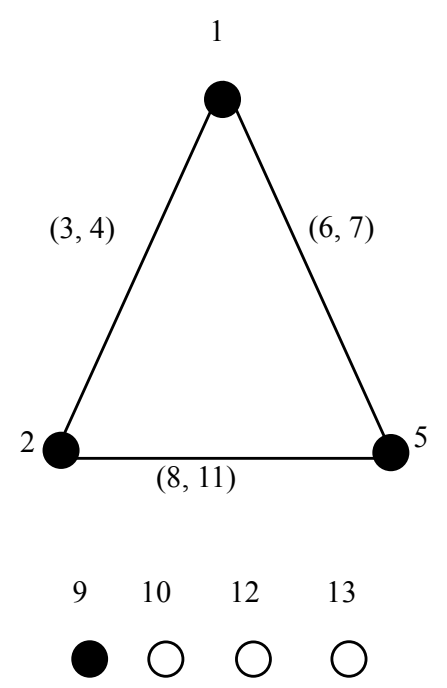

Figure 2. Linear graphs for $L_{27}$ array. 
The wear parameters chosen for the experiment are 1) sliding speed; 2) applied load; 3) sliding time; and 4) percentage of reinforcement of $\mathrm{SiC}$ and $\mathrm{B}_{4} \mathrm{C}$ materials. The experiment consists of 27 tests (each row in the $\mathrm{L}_{27}$ orthogonal array) and the columns were assigned with parameters. The first column was assigned to sliding speed (S), second column was assigned to applied load (L), fifth column was assigned to sliding time (T) and ninth column was assigned to percentage of reinforcement $(\mathrm{R})$ and the remaining columns were assigned to their interactions. The experiments were conducted as per the orthogonal array with level of parameters given in each array row. The output to be studied is wear rate and coefficients of friction of the test samples are repeated three times corresponding to 81 tests. The experimental observations are further transformed into Signal to noise ratio. The response to be studied was the wear rate and coefficient of friction with the objective as smaller the best, which is calculated as logarithmic transformation of loss function as shown below,

$$
\left(\frac{S}{N}\right)=-10 \times \log \frac{1}{n}\left(\sum Y_{i}^{2}\right)
$$

where " $n$ " is the numbers of observations, " $Y_{i}$ " is the measured value of wear rate and coefficient of friction. It is suggested that quality characteistics are optimised when the $S / N$ response is as smaller as possible.

\section{Results and Dissussion}

Experimental values of wear rate and coefficient of friction and the calculated values of signal to noise ratio for a given response using Equation (1), and are listed in Table 4. The Taguchi's technique suggested that the analyzing of signal to noise ratio using conceptual approach that involves graphing the special effects and visually making out the significant aspects.

Table 3. Orthogonal array $L_{27}\left(3^{13}\right)$ of taguchi method.

\begin{tabular}{|c|c|c|c|c|c|c|c|c|c|c|c|c|c|}
\hline $\mathrm{L}_{27}\left(3^{13}\right)$ & 1 & 2 & 3 & 4 & 5 & 6 & 7 & 8 & 9 & 10 & 11 & 12 & 13 \\
\hline 1 & 1 & 1 & 1 & 1 & 1 & 1 & 1 & 1 & 1 & 1 & 1 & 1 & 1 \\
\hline 2 & 1 & 1 & 1 & 1 & 2 & 2 & 2 & 2 & 2 & 2 & 2 & 2 & 2 \\
\hline 3 & 1 & 1 & 1 & 1 & 3 & 3 & 3 & 3 & 3 & 3 & 3 & 3 & 3 \\
\hline 4 & 1 & 2 & 2 & 2 & 1 & 1 & 1 & 2 & 2 & 2 & 3 & 3 & 3 \\
\hline 5 & 1 & 2 & 2 & 2 & 2 & 2 & 2 & 3 & 3 & 3 & 1 & 1 & 1 \\
\hline 6 & 1 & 2 & 2 & 2 & 3 & 3 & 3 & 1 & 1 & 1 & 2 & 2 & 2 \\
\hline 7 & 1 & 3 & 3 & 3 & 1 & 1 & 1 & 3 & 3 & 3 & 2 & 2 & 2 \\
\hline 8 & 1 & 3 & 3 & 3 & 2 & 2 & 2 & 1 & 1 & 1 & 3 & 3 & 3 \\
\hline 9 & 1 & 3 & 3 & 3 & 3 & 3 & 3 & 2 & 2 & 2 & 1 & 1 & 1 \\
\hline 10 & 2 & 1 & 2 & 3 & 1 & 2 & 3 & 1 & 2 & 3 & 1 & 2 & 3 \\
\hline 11 & 2 & 1 & 2 & 3 & 2 & 3 & 1 & 2 & 3 & 1 & 2 & 3 & 1 \\
\hline 12 & 2 & 1 & 2 & 3 & 3 & 1 & 2 & 3 & 1 & 2 & 3 & 1 & 2 \\
\hline 13 & 2 & 2 & 3 & 1 & 1 & 2 & 3 & 2 & 3 & 1 & 3 & 1 & 2 \\
\hline 14 & 2 & 2 & 3 & 1 & 2 & 3 & 1 & 3 & 1 & 2 & 1 & 2 & 3 \\
\hline 15 & 2 & 2 & 3 & 1 & 3 & 1 & 2 & 1 & 2 & 3 & 2 & 3 & 1 \\
\hline 16 & 2 & 3 & 1 & 2 & 1 & 2 & 3 & 3 & 1 & 2 & 2 & 3 & 1 \\
\hline 17 & 2 & 3 & 1 & 2 & 2 & 3 & 1 & 1 & 2 & 3 & 3 & 1 & 2 \\
\hline 18 & 2 & 3 & 1 & 2 & 3 & 1 & 2 & 2 & 3 & 1 & 1 & 2 & 3 \\
\hline 19 & 3 & 1 & 3 & 2 & 1 & 3 & 2 & 1 & 3 & 2 & 1 & 3 & 2 \\
\hline 20 & 3 & 1 & 3 & 2 & 2 & 1 & 3 & 2 & 1 & 3 & 2 & 1 & 3 \\
\hline 21 & 3 & 1 & 3 & 2 & 3 & 2 & 1 & 3 & 2 & 1 & 3 & 2 & 1 \\
\hline 22 & 3 & 2 & 1 & 3 & 1 & 3 & 2 & 2 & 1 & 3 & 3 & 2 & 1 \\
\hline 23 & 3 & 2 & 1 & 3 & 2 & 1 & 3 & 3 & 2 & 1 & 1 & 3 & 2 \\
\hline 24 & 3 & 2 & 1 & 3 & 3 & 2 & 1 & 1 & 3 & 2 & 2 & 1 & 3 \\
\hline 25 & 3 & 3 & 2 & 1 & 1 & 3 & 2 & 3 & 2 & 1 & 2 & 1 & 3 \\
\hline 26 & 3 & 3 & 2 & 1 & 2 & 1 & 3 & 1 & 3 & 2 & 3 & 2 & 1 \\
\hline 27 & 3 & 3 & 2 & 1 & 3 & 2 & 1 & 2 & 1 & 3 & 1 & 3 & 2 \\
\hline
\end{tabular}


Table 4. Orthogonal array and results of HMMC's.

\begin{tabular}{|c|c|c|c|c|c|c|c|c|}
\hline $\begin{array}{l}\text { Ex. } \\
\text { No }\end{array}$ & $\begin{array}{l}\text { Speed } \\
(\mathrm{m} / \mathrm{s}) \mathrm{S}\end{array}$ & $\begin{array}{l}\text { Load } \\
\text { (N) L }\end{array}$ & $\begin{array}{l}\text { Time } \\
(\min ) \mathrm{T}\end{array}$ & $\begin{array}{l}\text { Reinforcement } \\
\text { (\%) R }\end{array}$ & $\begin{array}{l}\text { Wear Rate } \\
\mathrm{mm}^{3} / \mathrm{m} \mathrm{Wr}\end{array}$ & $\begin{array}{l}\text { S/N Ratio for } \\
\text { Wear }(\mathrm{db})\end{array}$ & $\begin{array}{l}\text { Coefficient of } \\
\text { Friction Cf }\end{array}$ & $\begin{array}{c}\text { S/N Ratio for Coefficient } \\
\text { of Friction }(\mathrm{db})\end{array}$ \\
\hline 1 & 1.5 & 10 & 5 & 5 & 0.002354 & 52.563870 & 0.38348 & 8.325145 \\
\hline 2 & 1.5 & 10 & 10 & 10 & 0.001756 & 55.109509 & 0.32987 & 9.633143 \\
\hline 3 & 1.5 & 10 & 15 & 15 & 0.0012368 & 58.154010 & 0.306 & 10.28557 \\
\hline 4 & 1.5 & 20 & 5 & 10 & 0.0019123 & 54.368879 & 0.331 & 9.603440 \\
\hline 5 & 1.5 & 20 & 10 & 15 & 0.001348 & 57.406202 & 0.32 & 9.897000 \\
\hline 6 & 1.5 & 20 & 15 & 5 & 0.0025103 & 52.005487 & 0.39 & 8.178707 \\
\hline 7 & 1.5 & 40 & 5 & 15 & 0.001981 & 54.062310 & 0.3422 & 9.314399 \\
\hline 8 & 1.5 & 40 & 10 & 5 & 0.002782 & 51.112857 & 0.432 & 7.290325 \\
\hline 9 & 1.5 & 40 & 15 & 10 & 0.00231 & 52.727760 & 0.3623 & 8.818633 \\
\hline 10 & 3 & 10 & 5 & 10 & 0.001012 & 59.896389 & 0.30554 & 10.29863 \\
\hline 11 & 3 & 10 & 10 & 15 & 0.000739 & 62.627111 & 0.2867 & 10.85144 \\
\hline 12 & 3 & 10 & 15 & 5 & 0.00112 & 59.015639 & 0.35608 & 8.969048 \\
\hline 13 & 3 & 20 & 5 & 15 & 0.001039 & 59.667689 & 0.30335 & 10.36112 \\
\hline 14 & 3 & 20 & 10 & 5 & 0.00239 & 52.432041 & 0.3784 & 8.440977 \\
\hline 15 & 3 & 20 & 15 & 10 & 0.00168 & 55.493814 & 0.3213 & 9.861785 \\
\hline 16 & 3 & 40 & 5 & 5 & 0.002392 & 52.424776 & 0.4052 & 7.846611 \\
\hline 17 & 3 & 40 & 10 & 10 & 0.002076 & 53.655453 & 0.3418 & 9.324558 \\
\hline 18 & 3 & 40 & 15 & 15 & 0.00176 & 55.089746 & 0.322775 & 9.822002 \\
\hline 19 & 4.5 & 10 & 5 & 15 & 0.000613 & 64.250790 & 0.16677 & 15.55764 \\
\hline 20 & 4.5 & 10 & 10 & 5 & 0.001013 & 59.887811 & 0.28376 & 10.94097 \\
\hline 21 & 4.5 & 10 & 15 & 10 & 0.0007326 & 62.702661 & 0.2837 & 10.94281 \\
\hline 22 & 4.5 & 20 & 5 & 5 & 0.00173 & 55.239077 & 0.29918 & 10.48134 \\
\hline 23 & 4.5 & 20 & 10 & 10 & 0.001582 & 56.015870 & 0.27819 & 11.11316 \\
\hline 24 & 4.5 & 20 & 15 & 15 & 0.000998 & 60.017389 & 0.246 & 12.18129 \\
\hline 25 & 4.5 & 40 & 5 & 10 & 0.001672 & 55.535274 & 0.3222 & 9.837489 \\
\hline 26 & 4.5 & 40 & 10 & 15 & 0.001032 & 59.726406 & 0.31751 & 9.964851 \\
\hline 27 & 4.5 & 40 & 15 & 5 & 0.00186 & 54.609741 & 0.354 & 9.019934 \\
\hline
\end{tabular}




\subsection{Results of Statistical Analysis of Experiments}

The investigational results and calculated values were obtained based on the plan of experiment and then the results were analyzed with the help of commercial software MINITAB 14 as specially utilized for the design of experiment and statistical analysis of experiment appliances. The influence of controlled process parameters such as sliding speed, applied load, sliding time and percentage of reinforcement has been analyzed and the rank of involved factors like wear rate and coefficient of friction which supports signal to noise response is given in Tables 5 and 6.

It is evident from the tables that, among these parameters, load is a dominant factor on the wear rate and percentage of reinforcement for coefficient of friction. The influence of controlled process parameters on wear rate and coefficient of friction are graphically represented in Figures 3-6.
Table 5. Response for signal to noise ratio-smaller is better (wear rate).

\begin{tabular}{ccccc}
\hline Level & $\begin{array}{c}\text { Speed } \\
(\mathrm{m} / \mathrm{s})\end{array}$ & $\begin{array}{c}\text { Load } \\
(\mathrm{N})\end{array}$ & $\begin{array}{c}\text { Time } \\
(\mathrm{min})\end{array}$ & $\begin{array}{c}\text { Percentage of } \\
\text { Reinforcement \% }\end{array}$ \\
\hline 1 & 54.17 & 59.36 & 56.45 & 54.37 \\
2 & 56.70 & 55.85 & 56.44 & 56.17 \\
3 & 58.67 & 54.33 & 56.65 & 59.00 \\
Delta & 4.50 & 5.03 & 0.20 & 4.63 \\
Rank & 3 & 1 & 4 & 2 \\
\hline
\end{tabular}

Table 6. Response for signal to noise ratio-smaller is better (coefficient of friction).

\begin{tabular}{ccccc}
\hline Level & $\begin{array}{c}\text { Speed } \\
(\mathrm{m} / \mathrm{s})\end{array}$ & $\begin{array}{c}\text { Load } \\
(\mathrm{N})\end{array}$ & $\begin{array}{c}\text { Time } \\
(\mathrm{min})\end{array}$ & $\begin{array}{c}\text { Percentage of } \\
\text { Reinforcement \% }\end{array}$ \\
\hline 1 & 9.038 & 10.645 & 10.181 & 8.833 \\
2 & 9.531 & 10.013 & 9.717 & 9.937 \\
3 & 11.116 & 9.027 & 9.787 & 10.915 \\
Delta & 2.077 & 1.618 & 0.463 & 2.082 \\
Rank & 2 & 3 & 4 & 1 \\
\hline
\end{tabular}

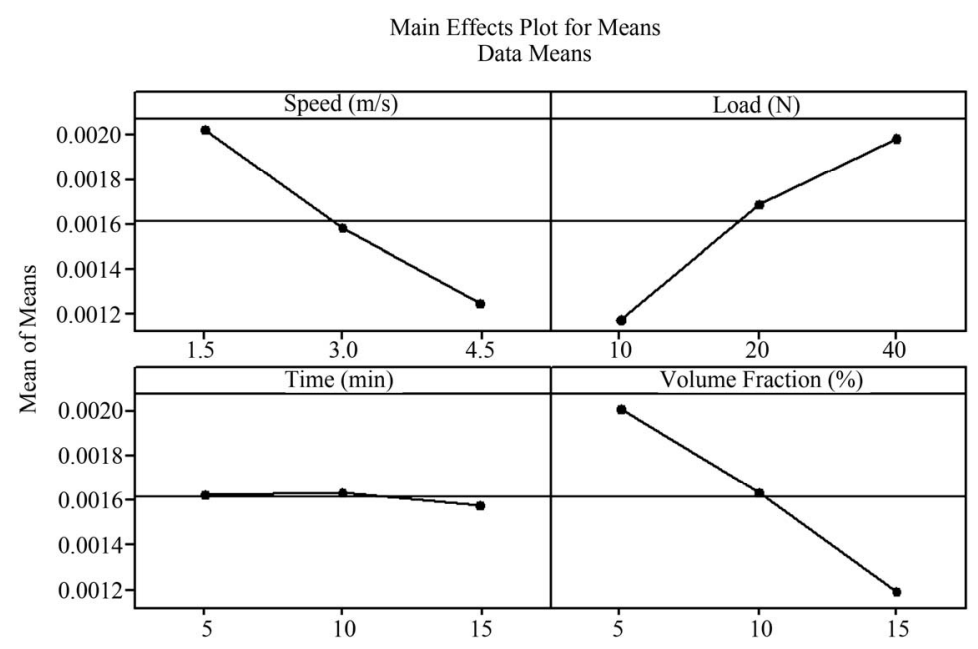

Figure 3. Main effects plot for means-wear rate.

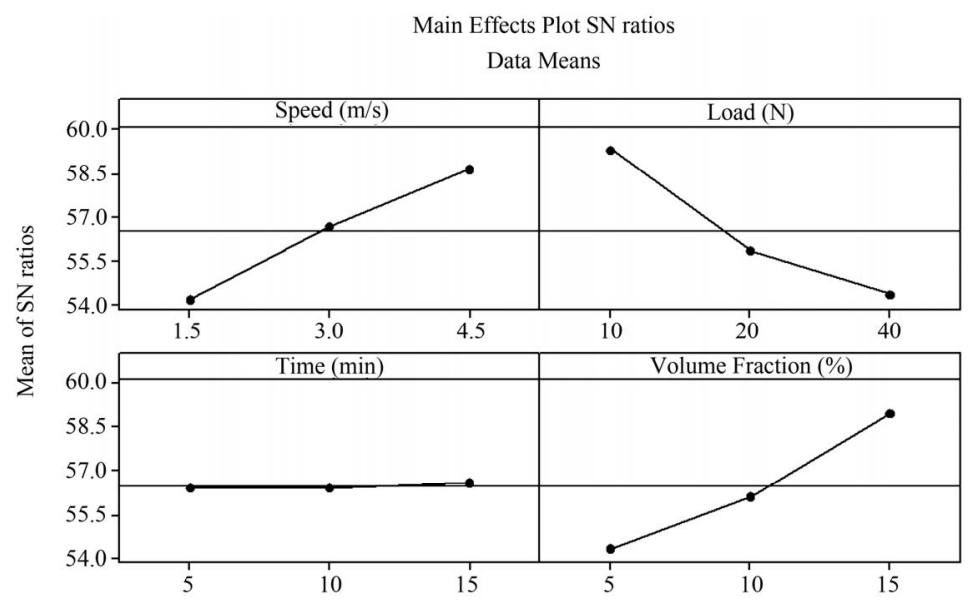

Signal-to-noise: Smaller is better

Figure 4. Main effects plot for $\mathrm{S} / \mathrm{N}$ ratios-wear rate. 


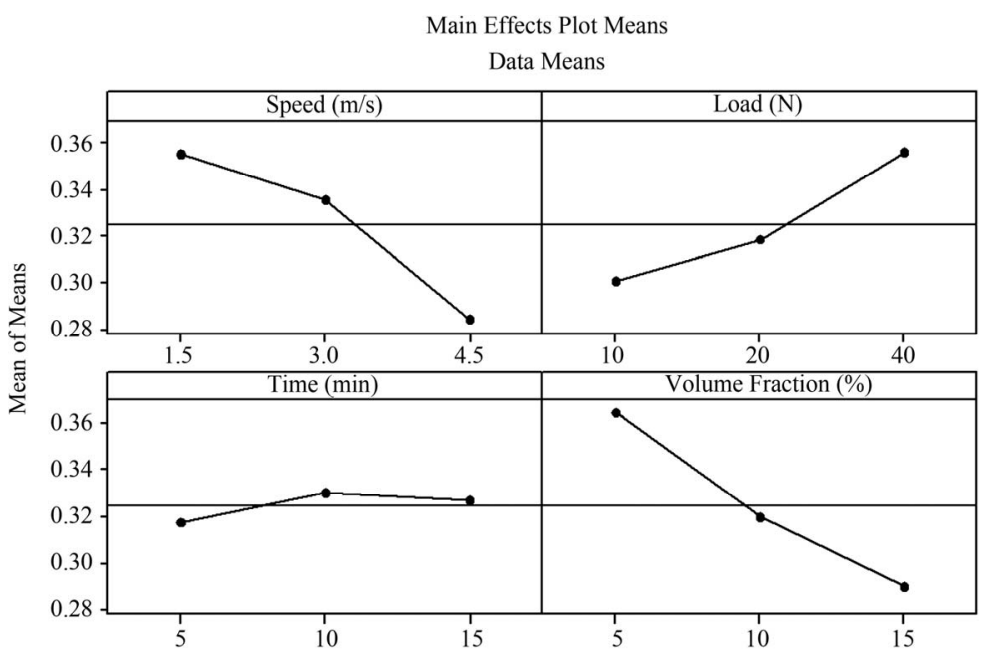

Figure 5. Main effects plot for means-coefficient of friction.

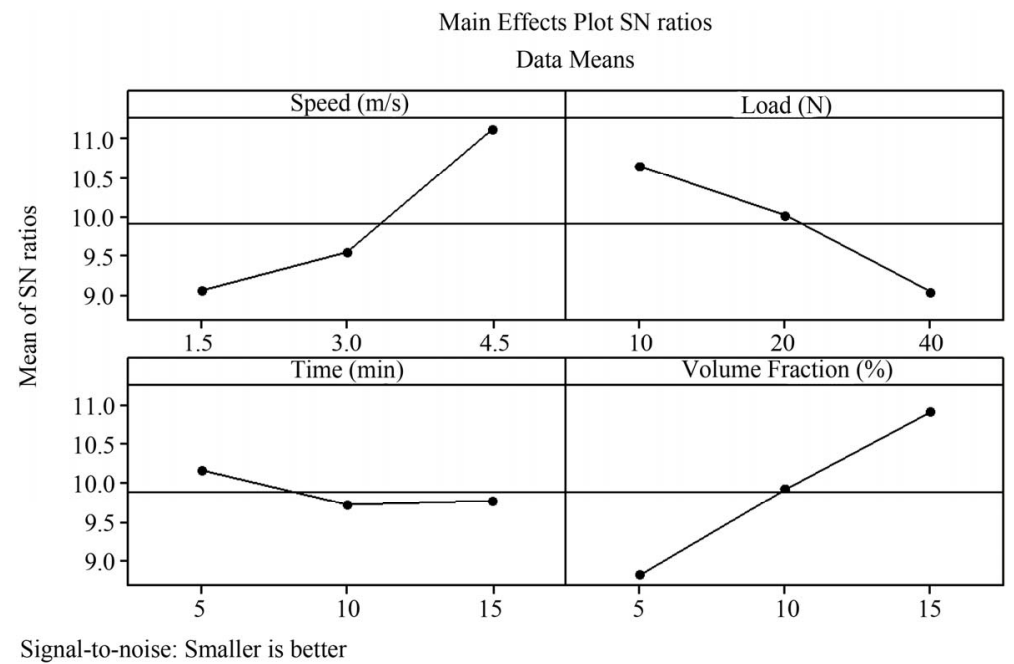

Figure 6. Main effects plot for $\mathrm{S} / \mathrm{N}$ ratios-coefficient of friction.

Based on the analysis of these experimental results with the help of signal to noise ratio, the optimum conditions resulting in wear rate and coefficient of friction are shown in Figures $\mathbf{4}$ and 6. The figures clearly indicate that the third level of sliding speed, first level of load and third level of both sliding time and percentages of reinforcement are the optimum points, but these optimum conditions are not available in $\mathrm{L}_{27}$ orthogonal array. Hence the optimum conditions tested separately and the results are given in Table 7.

\subsection{Analysis of Variance for Wear Rate}

Table 8 shows the results of the analysis of variance on the wear rate for $\mathrm{SiC}$ and $\mathrm{B}_{4} \mathrm{C}$ particulates reinforced Al-7075 alloy matrix composite. This analysis is carried out at a level of $5 \%$ significance that is up to a confidence level of $95 \%$. The last column of the table indicates the percentage of contribution ( $\mathrm{Pr}$ ) of each factor on the total variation indicating the degree of their influence on the results.

From Table 8, one can easily observe that the percentage of reinforcement factor has grater influence on wear rate $(\operatorname{Pr}-\mathrm{R}=30.99 \%)$. Hence the percentage of reinforcement is an important control process parameter to be taken into account while wear process. Percentage of reinforcement is further followed by applied load ( $\mathrm{Pr}-\mathrm{L}=$ $29.96 \%)$, sliding speed $(\mathrm{Pr}-\mathrm{S}=26.89 \%)$. Based on the interaction terms, the interaction between sliding speed and load alone have significance influence (Pr-S*L = $2.45 \%$ ) on wear rate of the hybrid metal matrix composites.

\subsection{Analysis of Variance for Coefficient of Friction}

From Table 9, one can clearly infer that the percentage of reinforcement factor has greater control on coefficient 
of friction ( $\mathrm{Pr}-\mathrm{R}=34.16 \%)$ than the other factors. Hence added percentage of reinforcement is an important parameter to be taken into account while considering coefficient of friction. This parameter is then followed by sliding speed $(\operatorname{Pr}-\mathrm{S}=33.31 \%)$, load $(\operatorname{Pr}-\mathrm{L}=18.89 \%)$, and sliding time $(\mathrm{Pr}-\mathrm{T}=0.18 \%)$. Based on the interaction terms, the interaction between load and sliding speed alone have significance influence $(\operatorname{Pr}-\mathrm{L} * \mathrm{~S}=1.59 \%)$ on coefficient of friction of the hybrid metal matrix composites.

Table 7. Optimum level process parameters for wear rate and coefficient of friction.

\begin{tabular}{|c|c|c|c|c|c|c|c|c|}
\hline $\begin{array}{l}\text { Ex. } \\
\text { No }\end{array}$ & $\begin{array}{l}\text { Speed } \\
(\mathrm{m} / \mathrm{s})\end{array}$ & $\begin{array}{l}\text { Load } \\
(\mathrm{N})\end{array}$ & $\begin{array}{l}\text { Time } \\
(\mathrm{min})\end{array}$ & $\begin{array}{c}\text { Percentage of } \\
\text { Reinforcement } \%\end{array}$ & $\begin{array}{l}\text { Wear Rate } \\
\mathrm{mm}^{3} / \mathrm{m}\end{array}$ & $\begin{array}{l}\text { S/N Ratio for } \\
\text { Wear }(\mathrm{db})\end{array}$ & $\begin{array}{l}\text { Coefficient } \\
\text { of Friction }\end{array}$ & $\begin{array}{l}\text { S/N Ratio for Coefficient of } \\
\text { Friction }(\mathrm{db})\end{array}$ \\
\hline 1 & 4.5 & 10 & 5 & 15 & 0.000613 & 64.25079 & 0.1667 & 15.55764 \\
\hline
\end{tabular}

Table 8. Analysis of variance for wear rate $\left(\mathrm{mm}^{3} / \mathrm{m}\right)$.

\begin{tabular}{|c|c|c|c|c|c|c|c|}
\hline Source & $\mathrm{DF}$ & Seq SS & Adj SS & Adj MS & $\mathrm{F}$ & $\mathrm{P}$ & $\operatorname{Pr} \%$ \\
\hline $\mathrm{S}(\mathrm{m} / \mathrm{sec})$ & 2 & 0.0000027 & 0.0000027 & 0.0000014 & 34.67702069 & 0.000504817 & 26.88556 \\
\hline $\mathrm{L}(\mathrm{N})$ & 2 & 0.000003 & 0.000003 & 0.0000015 & 37.15395074 & 0.000417041 & 29.96494 \\
\hline $\mathrm{T}$ (Min) & 2 & 0 & 0 & 0 & 0 & 1 & -0.82882 \\
\hline $\mathrm{R}(\%)$ & 2 & 0.0000031 & 0.0000031 & 0.0000015 & 37.15395075 & 0.000417041 & 30.99139 \\
\hline $\mathrm{S}(\mathrm{m} / \mathrm{sec}) * \mathrm{~L}(\mathrm{~N})$ & 4 & 0.0000004 & 0.0000004 & 0.0000001 & 2.476930049 & 0.153914958 & 2.44820 \\
\hline $\mathrm{L}(\mathrm{N}) * \mathrm{R}(\%)$ & 4 & 0.0000002 & 0.0000002 & 0 & 0 & 1 & 0.39529 \\
\hline $\mathrm{R}(\%) * \mathrm{~S}(\mathrm{~m} / \mathrm{sec})$ & 4 & 0.0000001 & 0.0000001 & 0 & 0 & 1 & -0.63117 \\
\hline Error & 6 & 0.0000036 & & & & & 10.77459 \\
\hline Total & 26 & 0.0000131 & & & & & 100 \\
\hline
\end{tabular}

Table 9. Analysis of variance for coefficient of friction.

\begin{tabular}{|c|c|c|c|c|c|c|c|}
\hline Source & $\mathrm{DF}$ & Seq SS & Adj SS & Adj MS & $\mathrm{F}$ & $\mathrm{P}$ & $\operatorname{Pr} \%$ \\
\hline $\mathrm{S}(\mathrm{m} / \mathrm{sec})$ & 2 & 0.0247533 & 0.0247533 & 0.0123766 & 41.6568802 & 0.000303179 & 33.3057555 \\
\hline $\mathrm{L}(\mathrm{N})$ & 2 & 0.0142994 & 0.0142994 & 0.0071497 & 24.06420125 & 0.001362003 & 18.89398901 \\
\hline $\mathrm{R}(\%)$ & 2 & 0.0253694 & 0.0253694 & 0.0126847 & 42.69370373 & 0.000283005 & 34.15511214 \\
\hline $\mathrm{S}(\mathrm{m} / \mathrm{sec}) * \mathrm{~L}(\mathrm{~N})$ & 4 & 0.0023454 & 0.0023454 & 0.0005863 & 1.973515588 & 0.21774874 & 1.594990663 \\
\hline $\mathrm{L}(\mathrm{N}) * \mathrm{R}(\%)$ & 4 & 0.0013486 & 0.0013486 & 0.0003371 & 1.134767256 & 0.422936085 & 0.220800281 \\
\hline Error & 6 & 0.0017827 & & & & & 10.64948465 \\
\hline Total & 26 & 0.0725373 & & & & & 100 \\
\hline
\end{tabular}




\subsection{Multiple Linear Regression Models}

Statistical software MINITAB R14 is used for developing a multiple linear regression equation. This developed model gives the relationship between independent/predictor variable and a response variable by fitting a linear equation to the measured data.

The regression equation developed for wear rate is,

$$
\begin{aligned}
\mathrm{Wr}= & 0.00268-0.000258 \mathrm{~S}(\mathrm{~m} / \mathrm{s})+0.000025 \mathrm{~L}(\mathrm{~N}) \\
& -0.000006 \mathrm{~T}(\mathrm{~min})-0.000082 \mathrm{R}(\%) \\
\mathrm{R}-\mathrm{Sq} & =86.5 \%
\end{aligned}
$$

The regression equation developed for coefficient of friction is,

$$
\begin{gathered}
\mathrm{Cf}=0.419-0.0239 \mathrm{~S}(\mathrm{~m} / \mathrm{s})+0.00185 \mathrm{~L}(\mathrm{~N}) \\
+0.000925 \mathrm{~T}(\mathrm{~min})-0.00745 \mathrm{R}(\%) \\
\mathrm{R}-\mathrm{Sq}=86.6 \%
\end{gathered}
$$

\subsection{Scanning Electron Microscope Examination}

Wear rate depends on the presence of carbide phase in matrix. Plates 7-9 show the SEM worn surface micrographs of reinforced samples. The pure Al-7075 has a smooth surface nature and more tribolayers are formed hence the wear rate is more in the unreinforced sample. The examination of hybrid composite sample worn surfaces as shown in Plates 7-9 showed that rough surface nature and less tribolayers due to silicon carbides and boron carbide embedded in matrix as compared to the unreinforced alloy.

\section{Confirmation Experiment}

Confirmation test is the last step in the plan process. Table $\mathbf{1 0}$ indicates the values used for conducting the dry sliding wear test and Table 11 shows the results of confirmation experiment and their comparison with regression model which helps to identify the optical parameter values from the experimental analysis. The mathematical model was developed with the help of regression Equations (2) and

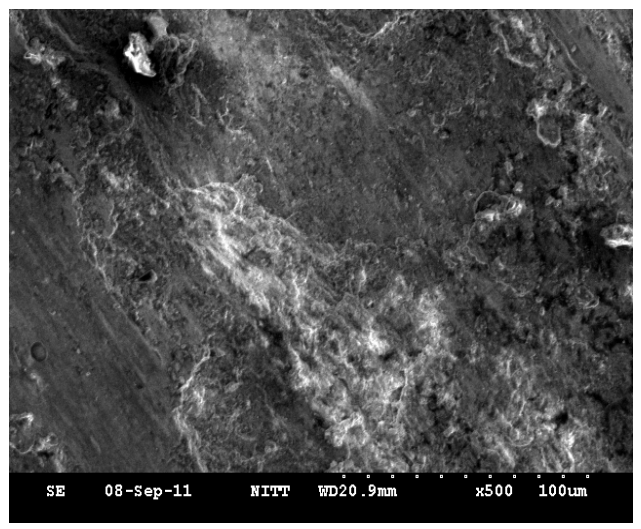

Plate 7. SEM texture of $5 \% \mathrm{SiC}+3 \% \mathrm{~B}_{4} \mathrm{C}$ particulate reinforced $\mathrm{Al}$ (7075) composite after wear.

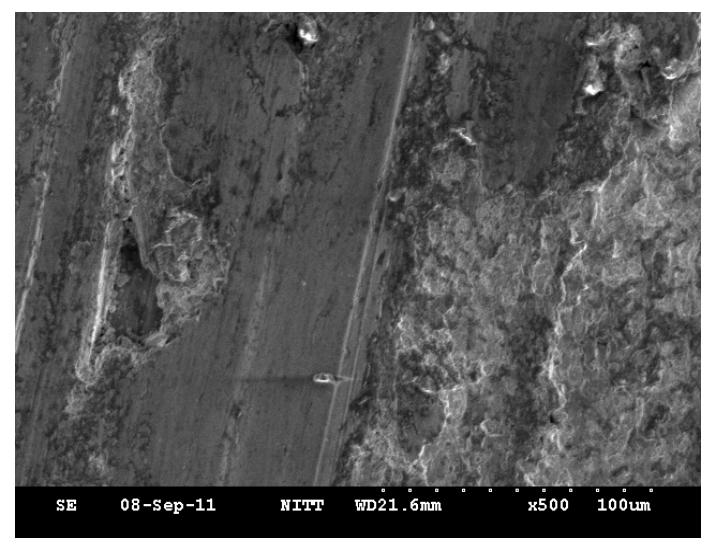

Plate 8. SEM texture of $10 \% \mathrm{SiC}+3 \% \mathrm{~B}_{4} \mathrm{C}$ particulate reinforced $\mathrm{Al}$ (7075) composite after wear.

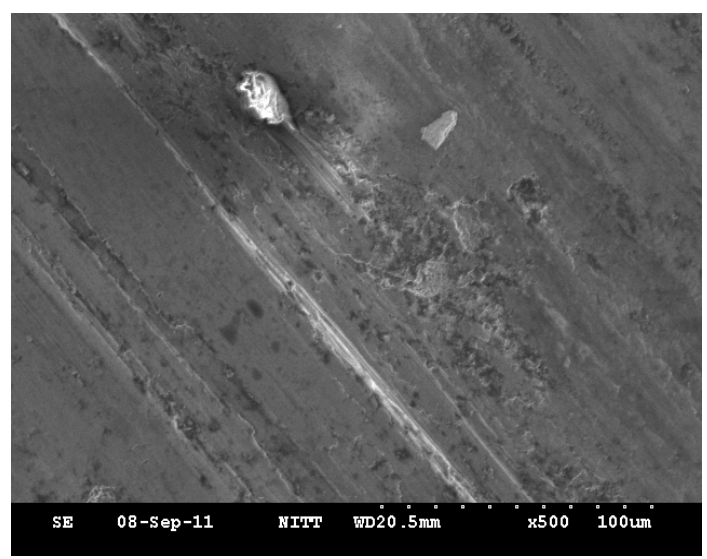

Plate 9. SEM texture of $15 \% \mathrm{SiC}+3 \% \mathrm{~B}_{4} \mathrm{C}$ particulate reinforced $\mathrm{Al}$ (7075) composite after wear.

Table 10. Confirmation experiment for wear rate and coefficient of friction.

\begin{tabular}{ccccc}
\hline Level & $\begin{array}{c}\text { Speed } \\
(\mathrm{m} / \mathrm{s})\end{array}$ & $\begin{array}{c}\text { Load } \\
(\mathrm{N})\end{array}$ & $\begin{array}{c}\text { Time } \\
(\mathrm{min})\end{array}$ & $\begin{array}{c}\text { Percentage of } \\
\text { Reinforcement \% }\end{array}$ \\
\hline 1 & 1.8 & 15 & 6 & 5 \\
2 & 3.3 & 25 & 9 & 10 \\
3 & 4.2 & 35 & 12 & 15 \\
\hline
\end{tabular}

(3) and also the comparison result values obtained experimentally were analyzed. From the analysis, the actual wear rate and coefficient of friction are found to be varying from the calculated one using regression equation and the error percentage ranges between $6.90 \%$ to $11.76 \%$ for wear rate and $4.66 \%$ to $9.23 \%$ for coefficient of friction. As these values are closely resembling the actual data with minimum error, design of experiments by Taguchi method was successful for calculating wear rate and coefficient of friction from the regression equation. Figure 7 shows a comparison between wear rate and coefficient of the obtained contribution percentage $(\operatorname{Pr} \%)$ of each factor with the source of variance. 
Table 11. Result of confirmation experiment and their comparison with regression model.

\begin{tabular}{cccccc}
\hline $\begin{array}{c}\text { Exp. } \\
\text { No }\end{array}$ & $\begin{array}{c}\text { Exp. wear rate } \\
\left(\mathrm{mm}^{3} / \mathrm{m}\right)\end{array}$ & $\begin{array}{c}\text { Reg. model Equation }(1), \\
\text { Wear Rate }\left(\mathrm{mm}^{3} / \mathrm{m}\right)\end{array}$ & \% Error & $\begin{array}{c}\text { Exp. coefficient } \\
\text { of friction }\end{array}$ & $\begin{array}{c}\text { Reg. model Equation (2), } \\
\text { coefficient of friction }\end{array}$ \\
\hline 1 & 0.002345549 & 0.0021446 & 9.37 & 0.4064 & 0.37203 \\
2 & 0.001688592 & 0.0015796 & 6.90 & 0.3473 & 0.32021 \\
3 & 0.001306921 & 0.0011694 & 11.76 & 0.2959 & 8.47 \\
\hline
\end{tabular}

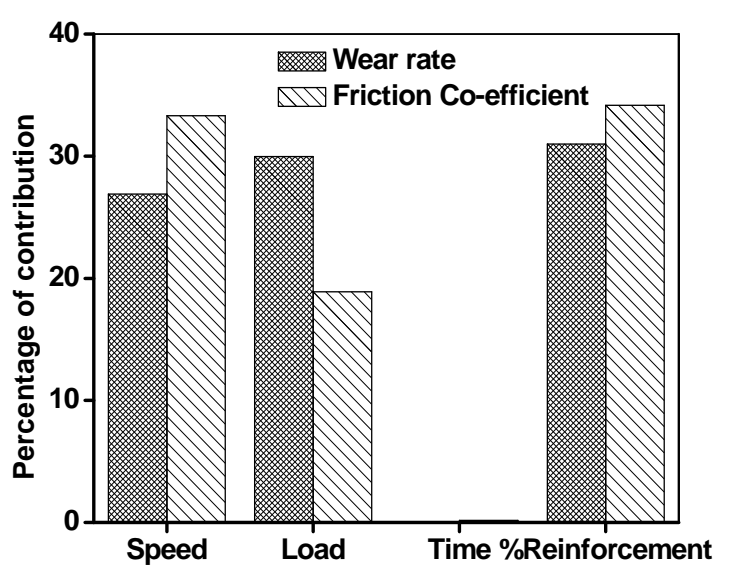

Figure 7. Wear and friction coefficient of contribution percentage (Pr\%).

\section{Conclusions}

Taguchi's method is used to find the optimum conditions for dry sliding wear of the hybrid metal matrix composite materials. The following are the conclusions drawn from the present study.

1) Optimum wear rate and coefficient of friction were obtained from the experiment.

2) The wear rate is dominated by different parameters in the order of percentage of reinforcement, applied load, sliding speed, and sliding time. ANOVA test concluded that as percentage of reinforcement increases the wear rate also decreases significantly.

3) Coefficient of friction is dominated by different parameters in the order of percentage of reinforcement, sliding speed, applied load, and sliding time.

4) $4.5 \mathrm{~m} / \mathrm{s}$ sliding speed, $10 \mathrm{~N}$ applied load, $5 \mathrm{~min}$ sliding time and $15 \%$ of reinforcement are the optimum conditions for both wear rate and the coefficient of friction.

5) Percentage of reinforcement (30.99\%) is the wear factor that has the highest physical properties as well as statistical influence on the dry sliding wear rate of the composites among the other factors such as applied load (29.96\%), sliding speed (29.89\%).

6) The interactions between the sliding speed and the applied load will contribute more $(2.45 \%)$ than other interactions.

7) The pooled error obtained with the help of Anova with respect to the parameters for wear rate and coefficient of friction are $10.78 \%$ and $10.65 \%$ respectively.
The multiple regression values obtained for wear rate and coefficient of friction are 0.865 and 0.866 respectively.

8) From confirmation tests, the errors associated with wear rate ranges between $6.90 \%$ to $11.76 \%$ and $4.66 \%$ to $9.23 \%$ for coefficient of friction resulting in the conclusion that the design of experiments by Taguchi method was successful for calculating wear rate and coefficient of friction from the regression equation.

\section{Acknowledgements}

The authors would like to express their deep sense of gratitude to Prof. P. Suresh Kumar, Assistant Professor, Department of Mechanical Engineering at Bannari Amman Institute of Technology, Sathyamagalam, for his valuable support and guidance. They also extend their gratefulness to Mr. S. Sudhakar, Assistant Manager, BEML Ltd., Mysore, for his constant guidance and discussion throughout the research work. The authors also would like to thank their M.E., Students for all their supports. The authors would like to extend their gratitude to Bannari Amman Institute of Technology for providing infrastructural support.

\section{REFERENCES}

[1] S. J. Harris, "Cast Metal Matrix Composites," Materials Science and Technology, Vol. 4, No. 3, 1988, pp. 231239. doi: $10.1179 / 026708388790330024$

[2] Y. Iwai, H. Yonede and T. Honda, "Sliding Wear Behaviour of SiC Whisker-Reinforced Aluminum Composite," Wear, Vol. 181-183, No. 2, 1995, pp. 594-602. doi:10.1016/0043-1648(95)90175-2

[3] A. Daoud, M. T. Abou El-Khair and A. N. Abdel-Azim, "Microstructure and Wear Behavior of Squeeze Cast $7075 \mathrm{Al}-\mathrm{Al}_{2} \mathrm{O}_{3}$ Particle Composites," Proceedings of the 14th International Offshore and Polar Engineering Conference, Toulon, 23-28 May 2004, p. 252.

[4] S. V. Prasad and R. Asthana, "Aluminum Metal-Matrix Composites for Automotive Applications," Tribology Letters, Vol. 17, No. 3, 2004, pp. 445-453. doi:10.1023/B:TRIL.0000044492.91991.f3

[5] N. Natarajan, S. Vijayarangan and I. Rajendran, "Wear Behaviour of A356/25 $\mathrm{SiC}_{\mathrm{p}}$ Aluminium Matrix Composites Sliding Against Automobile Friction Material," Wear, Vol. 261, No. 7-8, 2006, pp. 812-822. doi:10.1016/j.wear.2006.01.011

[6] S. Basavarajappa and G. Chandramohan, "Wear Studies 
on Metal Matrix Composites: A Taguchi Approach," Journal of Material Science Technology, Vol. 21, No. 6, 2005, pp. 845-850.

[7] N. Radhika, R. Subramanian and S. Venkat Prasat, "Tribological Behaviour of Aluminium/Alumina/Graphite Hybrid Metal Matrix Composite Using Taguchi's Techniques," Journal of Minerals \& Materials Characterization \& Engineering, Vol. 10, No. 5, 2011, pp. 427-443.

[8] K. Umanath, S. T. Selvamani and K. Palanikumar, "Friction and Wear Behaviour of Al-6061 Alloy $\left(\mathrm{SiC}_{\mathrm{p}}+\right.$ $\mathrm{Al}_{2} \mathrm{O}_{3 \mathrm{p}}$ ) Hybrid Composites," International Journal of
Engineering Science and Technology, Vol. 3, No. 7, 2011, pp. 5441-5451.

[9] P. J. Ross, "Taguchi Techniques for Quality Engineering," 2nd Edition, McGraw-Hill Book Co., New York, 1996, pp. 23-42.

[10] Siddhartha, A. Patnaik and A. D. Bhatt, "Mechanical and Dry Sliding Wear Characterization of Epoxy-TiO 2 Particulate Filled Functionally Graded Composite Materials Using Taguchi Design of Experiment," Material \& Design, Vol. 32, No. 2, 2011, pp. 615-627. doi:10.1016/j.matdes.2010.08.011 